Copyright by the American Institute of Physics (AIP). Skandani, A. Alipour; Masghouni, N.; Case, S. W.; et al., "Enhanced

vibration damping of carbon fibers-Zno nanorods hybrid composites," Appl. Phys. Lett. 101, 073111 (2012); http:// dx.doi.org/10.1063/1.4746398

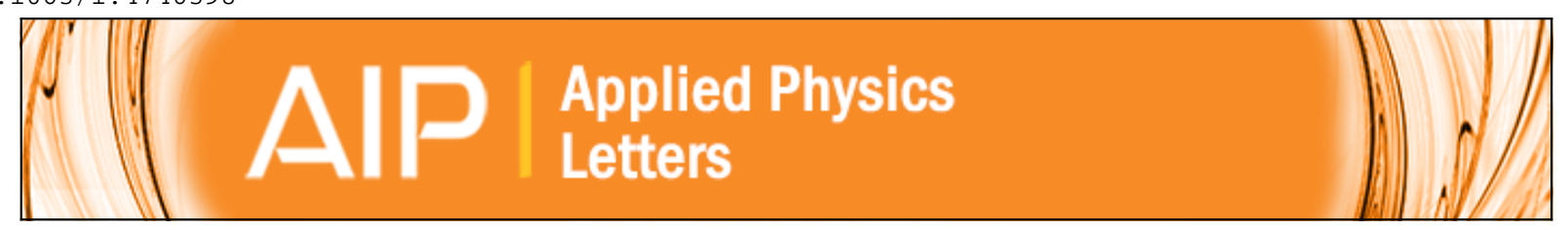

Enhanced vibration damping of carbon fibers-ZnO nanorods hybrid composites

A. Alipour Skandani, N. Masghouni, S. W. Case, D. J. Leo, and M. Al-Haik

Citation: Applied Physics Letters 101, 073111 (2012); doi: 10.1063/1.4746398

View online: http://dx.doi.org/10.1063/1.4746398

View Table of Contents: http://scitation.aip.org/content/aip/journal/apl/101/7?ver=pdfcov

Published by the AIP Publishing

AIP Re-register for Table of Content Alerts 


\title{
Enhanced vibration damping of carbon fibers-ZnO nanorods hybrid composites
}

\author{
A. Alipour Skandani, ${ }^{1}$ N. Masghouni, ${ }^{1}$ S. W. Case, ${ }^{1}$ D. J. Leo, ${ }^{2}$ and M. Al-Haik ${ }^{1, a)}$ \\ ${ }^{1}$ Department of Engineering Science \& Mechanics, Virginia Tech, Blacksburg, Virginia 24061, USA \\ ${ }^{2}$ Department of Mechanical Engineering, Virginia Tech, Blacksburg, Virginia 24061, USA
}

(Received 25 June 2012; accepted 1 August 2012; published online 17 August 2012)

\begin{abstract}
In this study, $\mathrm{ZnO}$ nanorods are grown on the surface of polyacrylonitrile based carbon fibers using a low temperature hydrothermal synthesis technique. Bi-layered carbon fiber-ZnO nanorod hybrid composite with epoxy matrix is prepared and tested for vibrational attenuations using dynamic mechanical analysis. Results revealed that the growth of $\mathrm{ZnO}$ nanorods on top of carbon fiber increases the damping performance by $50 \%$ while causing a slight decrease $(\sim 7 \%)$ on the storage modulus. The enhanced damping of the hybrid composites can be related to the frictional mechanisms between the $\mathrm{ZnO}$ nanorod/epoxy and nanorod/nanorod interfaces combined with piezoelectric effect of $\mathrm{ZnO}$. (C) 2012 American Institute of Physics.
\end{abstract}

[http://dx.doi.org/10.1063/1.4746398]

Due to several cost and processing impediments, several investigations departed from introducing nanomaterials directly into polymeric hosts. Alternatively, the concept of hybrid fibers has emerged. These fibers comprise standard structural fibers (e.g., carbon, fiberglass, aramid, or $\mathrm{SiC}$ ) with surface grown nano-fibers or nanotubes (e.g., carbon nanotubes $^{1}$ or $\mathrm{ZnO}$ nanorods ${ }^{2}$ ). The motivation of growing 1D metal oxide nano-structures in general and $\mathrm{ZnO}$ nanorods in particular over structural and conductive fibers commences from their contribution to a wide range of applications such as smart materials for energy scavenging, ${ }^{3}$ improved mechanical behavior through better matrix-to-fiber adhesion, ${ }^{2,4}$ gas sensors, ${ }^{5}$ field emission, ${ }^{6}$ photo-electrochemical cells, ${ }^{7}$ surface polarity shielding, ${ }^{8}$ and improved damage resistance. ${ }^{9}$ Fiber reinforced polymer (FRP) composites can dissipate some energy on their own due to the fiber and matrix elastic/viscoelastic behaviors. However, traditional FRPs suffer from insufficient vibrations attenuation. ${ }^{10}$ Consequently, an enormous interest is exalted to boost the vibration damping properties of FRPs while retaining their light weight and in-plane structural properties. Energy dissipation mechanisms can be elevated by embedding a viscoelastic layer between the laminates at the cost of lowering the strength and stiffness, ${ }^{11}$ fibers' surface treatment, ${ }^{12}$ addition of nano-fillers ${ }^{11,13}$ and matrix modification via viscoelastic particles. ${ }^{14}$

The slippage and frictional mechanisms at the filler/matrix interfaces are the main culprits for improving the FRPs' damping and for the case of nanoscale high-aspect ratio fillers (e.g., carbon nanotubes) these mechanisms are even more pronounced. ${ }^{15,16}$ The effectiveness of these nano-fillers in improving the FRP damping relies on their volume fraction, morphology, and distribution within the matrix. Carbon nanotubes for instance showed maximum damping improvement when their volume fraction exceeded the mechanical percolation threshold. ${ }^{16}$ However, reported improvement of damping utilizing CNTs showed considerable discrepancies from zero to $700 \%$ due to unresolved agglomeration and poor dispersion

a)E-mail: alhaik@vt.edu. of the nanotubes. ${ }^{17,18}$ The high surface areas together with the Van der Wall forces between the tubes compel them to entangle and form micron-sized agglomerates. Various mechanical techniques such as sonicating, ${ }^{16,19}$ calendaring, ${ }^{20}$ and prolonged shear mixings ${ }^{16}$ were utilized to obtain reasonable dispersion of CNTs within polymer matrices.

Interfacial reinforcement through whiskerization by growing a secondary reinforcing material directly on the fiber surface is proven to have several advantages over regular surface modification methods. ${ }^{2}$ Selective growth of nanotubes on designated surfaces yielded better damping where up to $1400 \%$ improvement in the damping figure of merit was reported. $^{21}$

Zinc oxide has high piezoelectric tensor providing large electromechanical coupling due to its wide band-gap $(3.37 \mathrm{eV})$ and the absence of an inversion symmetry in its wurtzite structure. $^{22}$ The superior stability of the $\pm(0001)$ polar surfaces makes it relatively easy for zinc oxide embryos to initiate a directional growth and create $1 \mathrm{D}$ and $2 \mathrm{D}$ nanostructures such as nanowires, nanorods, flower-like and cabbagelike structures, tubes, and rings. ${ }^{22,23}$ Established techniques for synthesizing $\mathrm{ZnO}$ nanorods and nanowires include chemical vapor deposition (CVD), ${ }^{24}$ electrodeposition, ${ }^{23}$ hydrothermal, and templated growth. ${ }^{25}$ These techniques can be employed to grow $\mathrm{ZnO}$ nanostructures over different substrates; however, most of them require a preexisting zinc oxide layer or another substrate with matching lattice parameters to be able to initiate the growth. This self-catalytic substrate layer can be deposited via physical or chemical routes. ${ }^{23}$

Degradation of carbon fibers under high temperatures is well-known, ${ }^{17,26}$ therefore, it is crucial to employ $\mathrm{ZnO}$ synthesis route that requires low temperatures. Hydrothermal synthesis is a low-temperature solution-based growth which can be conducted at $60^{\circ} \mathrm{C}-90^{\circ} \mathrm{C}$. The aqueous solution comprises zinc acetate $\mathrm{Zn}\left(\mathrm{O}_{2} \mathrm{CCH}_{3}\right)_{2}$ or zinc nitrate $\mathrm{Zn}\left(\mathrm{NO}_{3}\right)_{2}$ as the source for $\mathrm{Zn}^{2+}$ ions in water while the $\mathrm{H}_{2} \mathrm{O}$ molecules supply the $\mathrm{O}^{2-}$ ions. The role of the nonionic cyclic tertiary amine, hexamethylenetetramine (HMTA) is not yet fully understood. ${ }^{23}$ To probe any undesirable effect of the hydrothermal 
synthesis on the base carbon fibers, mechanical tests were performed on single carbon fibers coated individually with $\mathrm{ZnO}$ nanorods. ${ }^{2,4,27}$ However, FRPs utilize bundles of woven fibers rather than single fibers and the weave architecture plays a critical role on the composite properties.

The purpose of this study is to grow $\mathrm{ZnO}$ nanorods on the surface of carbon fibers with woven architecture and regular grades of sizing, process a FRP based on this hybrid structure and investigate their vibration damping.

Commercial high strength polyacrylonitrile (PAN)based plain-woven carbon fabric (AS2C supplied by HEXCEL Inc.) with $3 \mathrm{k}$ bundles were employed as the substrate for $\mathrm{ZnO}$ nanorods growth. To initiate the crystallization and growth of $\mathrm{ZnO}$ nanorods, an $80 \mathrm{~nm} \mathrm{ZnO}$ thin film was deposited on the carbon fabrics (both sides) using a magnetron sputtering system (ATC Orion high vacuum sputtering system, AJA International Inc.). Zinc acetate hexahydrate $\left(\mathrm{Zn}\left(\mathrm{O}_{2} \mathrm{CCH}_{3}\right)_{2} \cdot 6 \mathrm{H}_{2} \mathrm{O}\right)$ and HMTA were dissolved in deionized (DI) water with $20 \mathrm{mM}$ concentration for each. Double side $\mathrm{ZnO}$ coated fabrics with $13 \times 13 \mathrm{~cm}^{2}$ surface area were suspended in a sealed container filled with the prepared solution and kept at $80^{\circ} \mathrm{C}$ for $12 \mathrm{~h}$ using a convection furnace. Two other sets of samples one with $80 \mathrm{~nm} \mathrm{ZnO}$ film and one based on the bare fibers (without $\mathrm{ZnO}$ film) were placed in a $20 \mathrm{mM}$ HMTA/DI water solution for $12 \mathrm{~h}$ at $80^{\circ} \mathrm{C}$ to investigate the effect of the solution on the final properties of the samples. Also, a reference set of samples were prepared using dry bare carbon fabrics. Upon finishing the growth step, the hybrid fabrics with surface grown $\mathrm{ZnO}$ were utilized to manufacture bi-layered composites via standard hand lay-up process. The matrix material was a resin based epoxy, Aeropoxy ${ }^{\mathrm{TM}}$ manufactured by PTM\&W Industries, Inc.

Electron scanning microscopy (LEO (Zeiss) 1550 fieldemission SEM) was utilized to study the size and morphology of the grown nanorods as well as possible effects of solution environment on the sizing of fibers. SEM was also used to study the composites inter-laminar interfaces in terms of delamination and defects. To probe the crystallinity and purity of the grown $\mathrm{ZnO}$ nanorods, $\mathrm{x}$-ray diffraction (Philips Xpert Pro with $\mathrm{Cu}-\mathrm{K} \alpha$ lamp and Ni filter) was employed on all four configurations of samples. After $24 \mathrm{~h}$ curing at room temperature, the composite specimens were cut into rectangular coupons of $12.0 \times 60.0 \times 0.4 \mathrm{~mm}$ and tested using dynamic mechanical analysis (DMA) Q800 tester (TA Instruments, Inc.). Tests were performed following ASTM D5418-07 under a frequency range of $1-25 \mathrm{~Hz}, 0.1 \%$ strain, and room temperature with dual cantilever clamps.

SEM micrograph of hydrothermally grown $\mathrm{ZnO}$ nanorods on the surface of AS2C carbon fibers is illustrated in Figures 1(a)-1(c). It can be realized that the $\mathrm{ZnO}$ growth took place over the entire bundle (Figure 1(a)) and the $\mathrm{ZnO}$ nanorods are aligned radially with respect to the fibers (Figure 1(b)) while maintaining an almost uniform length and distribution; Figure 1(c). To examine the attachment of nanorods to the carbon fibers after the hand lay-up processwhere high vacuum and pressure are applied-another SEM micrograph was taken for the composite sample. Figure 1(d) delineates the inter-laminar interface of the bi-layered composite where it can be seen that the nanorods are well aligned and are still intact with the upper and lower fibers.

Figure 2 depicts the SEM micrographs of the carbon fibers exposed to the $20 \mathrm{mM}$ HMTA/DI water solution for $12 \mathrm{~h}$ at $80^{\circ} \mathrm{C}$. The figure suggests that the solution peeled off and ruptured the sizing into flakes.

Plotted in Figure 3 are the XRD patterns for the different treated carbon fibers configurations. It can be interpreted form these patterns that the exposure to the growth solution without zinc acetate (soaked fibers) does not alter the structure of the carbon fibers in comparison to the raw fibers. The fibers sputtered with the $80 \mathrm{~nm} \mathrm{ZnO}$ thin film do not show any trace of the zinc oxide due to the amorphous state of the
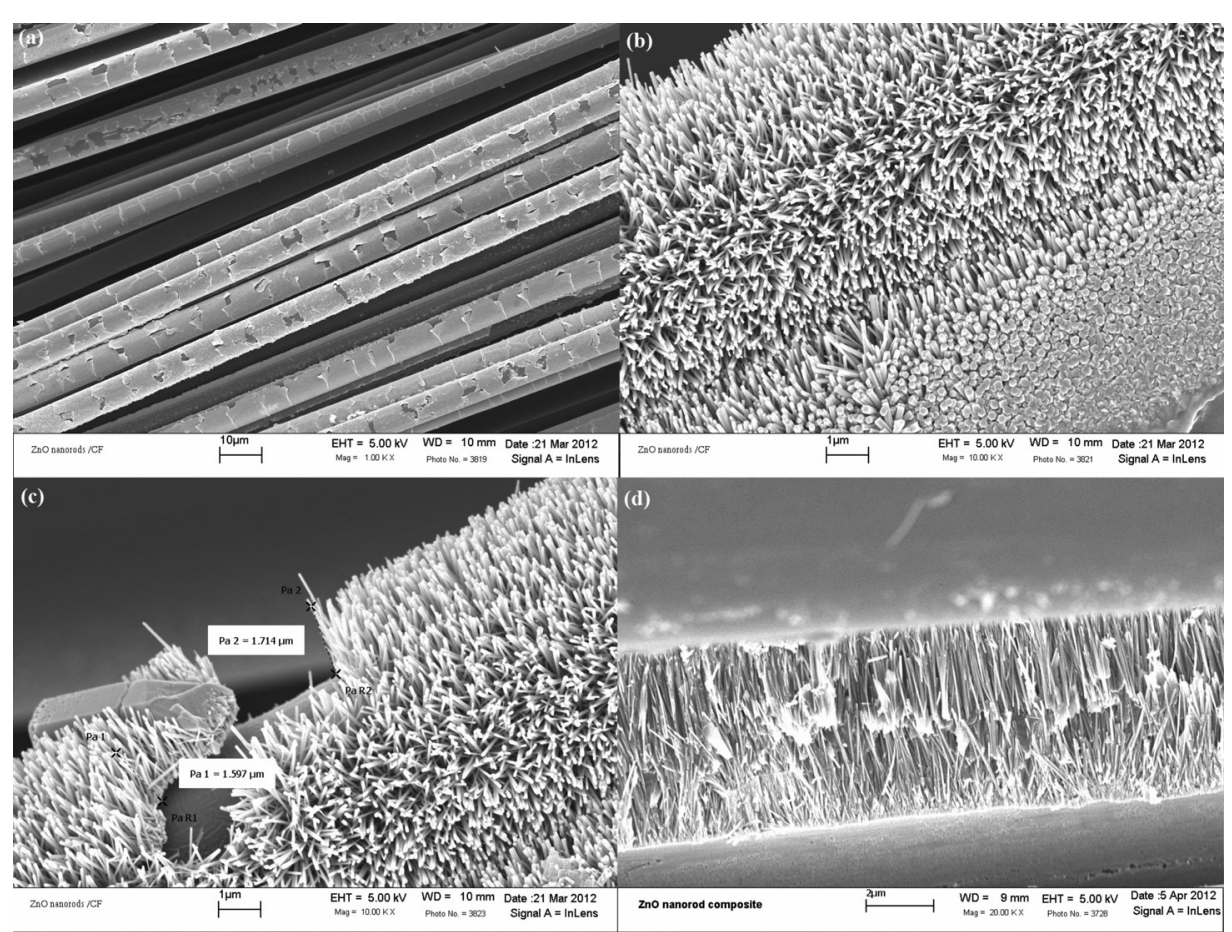

FIG. 1. SEM micrograph of hydrothermally grown $\mathrm{ZnO}$ nanorods (a)-(c) before and (d) after hand lay-up process. 


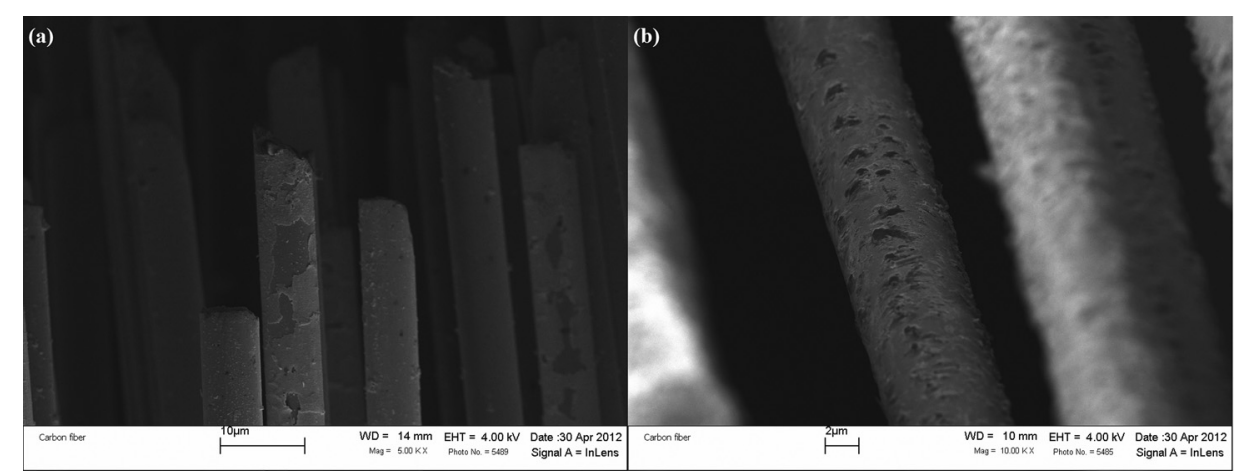

FIG. 2. SEM micrograph of samples exposed to growth solution without zinc acetate at (a) $5 \mathrm{k}$ and (b) $10 \mathrm{k}$ magnifications.

deposited film while the fibers with surface grown $\mathrm{ZnO}$ nanorod (labeled by growth in Figure 3) show sharp signature peaks of $\mathrm{ZnO}$. The appearance of all the $\mathrm{ZnO}$ characteristic peaks is indicative of the high crystalline nature of grown nanorods.

DMA tests provide the viscoelastic properties of a material such as the storage modulus $\left(E^{\prime}\right)$ as measure of dynamic stiffness, loss modulus $\left(E^{\prime \prime}\right)$ as a measure for energy dissipation and the tangent of phase angle between the stress and strain vectors linking these two moduli $\left(\tan (\delta)=\frac{E^{\prime}}{E}\right)$. Figure 4 depicts the plots of the storage modulus and $\tan (\delta)$ for all the samples in a frequency range of $1-25 \mathrm{~Hz}$ and strain of $0.1 \%$ at ambient temperature. It can be discerned that the storage modulus is not frequency-dependent whereas $\tan (\delta)$ varies dramatically with the frequency. The three samples exposed to the solution with/without zinc acetate (i.e., soaked, sputtered, and growth) exhibit identical storage moduli, however, they are slightly lower than that for the reference samples (raw).

The reason for this drop (which is $7 \%$ at most) is mainly due to the damaged sizing of carbon fibers under growth condition (Figure 2). Nevertheless, compared to the degradation of the storage modulus due to high temperature synthesis techniques, ${ }^{16}$ the effect of the solution on the carbon fibers is marginal. On the other hand, $\tan (\delta)$ for the composites samples with $\mathrm{ZnO}$ growth is considerably higher in comparison with the other three samples. At lower frequencies, the composites with $\mathrm{ZnO}$ nanorods showed up to $50 \%$ improvement in

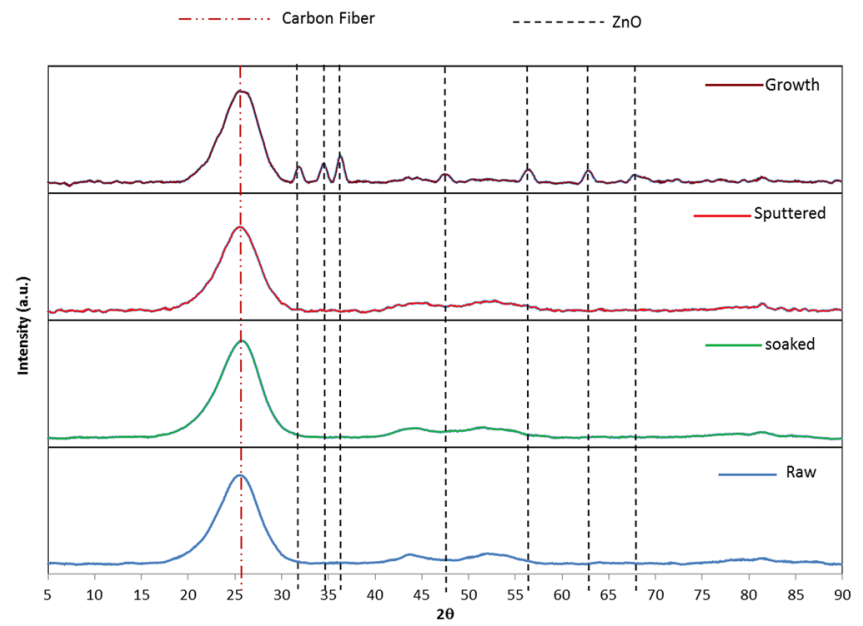

FIG. 3. XRD patterns for all four fibers configurations: raw (non-processed), soaked (soaked in solution), sputtered ( $\mathrm{ZnO}$ coated and soaked in solution), and growth (with surface grown $\mathrm{ZnO}$ nanorods). passive damping compared to the other samples. The main contributors to this enhanced damping are the frictional and slippage mechanisms in the presence of high surface area/ high aspect ratio $\mathrm{ZnO}$ nanorods. A lesser portion of this
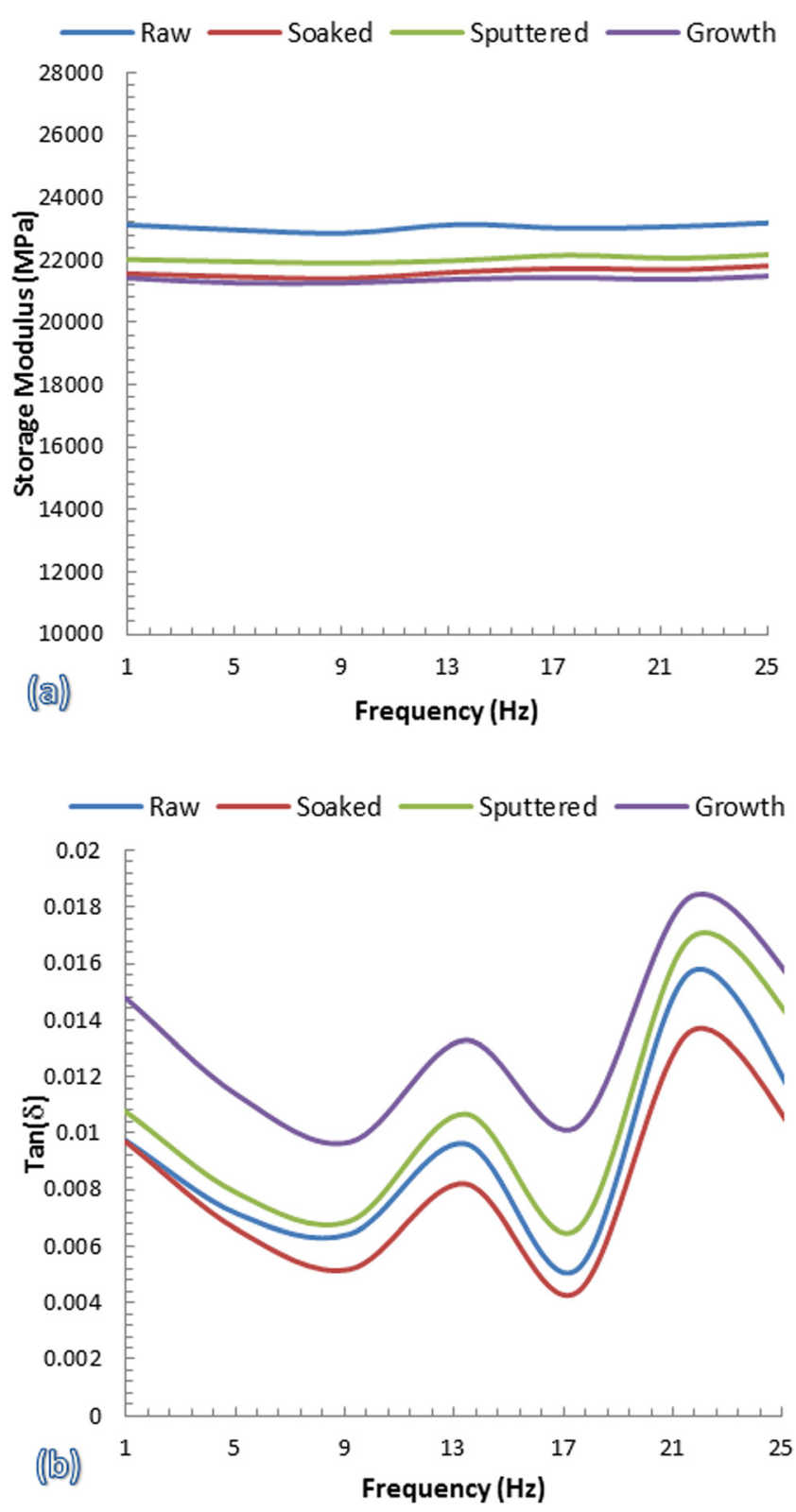

FIG. 4. (a) Storage modulus and (b) $\tan (\delta)$ for composites made out of raw (non-processed), soaked (soaked in solution), sputtered ( $\mathrm{ZnO}$ coated and soaked in solution), and growth (with surface grown $\mathrm{ZnO}$ nanorods) woven carbon fibers. 
damping can be attributed to the piezoelectric effect of $\mathrm{ZnO}$ which is in agreement with several reports on the damping properties of $\mathrm{ZnO}$ particulates when embedded in polymer matrices as a result of their electromechanical coupling. ${ }^{28}$ It is also observed that the samples sputtered with $\mathrm{ZnO}$ but with no nanorods growth showed improved damping over the raw and soaked samples which can be attributed to the increased interfacial surfaces between the fibers and the sputtered $\mathrm{ZnO}$ layer.

In summary, it was shown that $\mathrm{ZnO}$ nanorods can be surface-grown via hydrothermal synthesis technique without considerable changes on the microstructure or the properties of PAN-carbon fibers. X-ray diffraction and scanning electron microcopy analysis showed that the grown $\mathrm{ZnO}$ nanorods are uniformly distributed, fully crystalline, and maintain good adherence to the carbon fibers even after the high vacuum/pressure processing of the FRP. The applicability of these carbon fiber/ZnO nanorods hybrids in structural FRPs was demonstrated and the results of the DMA tests proven them to be advantageous for structural damping applications. The enhanced damping properties of the hybrid composites are attributed to the frictional sliding mechanisms of the high surface area/high aspect ratio $\mathrm{ZnO}$ nanorods grown uniformly throughout the FRP. This attenuation can also be related in part to electromechanical coupling of $\mathrm{ZnO}$ as well.

This work has been supported partially by the Office of Naval Research (ONR) Grant No. 0960991 and the Institute for Critical Technology and Applied Science (ICTAS) at Virginia Tech.

${ }^{1}$ M. Al-Haik, J. Dai, D. Garcia, J. Chavez, M. R. Taha, C. Luhrs, and J. Phillips, Nanosci. Nanotechnol. Lett. 1(2), 122 (2009); C. Luhrs, D. Garcia, M. Tehrani, M. Al-Haik, M. RedaTaha, and J. Phillips, Carbon 47(13), 3071 (2009).

${ }^{2}$ G. J. Ehlert, Y. Lin, U. Galan, and H. A. Sodano, J. Solid Mech. Mater. Eng. 4(11), 1687 (2010).

${ }^{3}$ Y. Qin, X. Wang, and Z. L. Wang, Nature 451(7180), 809 (2008); Z. L. Wang, and J. Song, Science 312(5771), 242 (2006).
${ }^{4}$ U. Galan, Y. Lin, G. J. Ehlert, and H. A. Sodano, Compos. Sci. Technol. 71(7), 946 (2011); U. Galan, G. J. Ehlert, Y. Lin, and H. A. Sodano, Mater. Res. Soc. Symp. Proc. 1174, 1174 (2009).

${ }^{5}$ M. Tonezzer and R. G. Lacerda, Sens. Actuators B 150(2), 517 (2010).

${ }^{6}$ S. H. Jo, D. Banerjee, and Z. F. Ren, Appl. Phys. Lett. 85(8), 1407 (2004).

${ }^{7}$ H. E. Unalan, D. Wei, K. Suzuki, S. Dalal, P. Hiralal, H. Matsumoto, S. Imaizumi, M. Minagawa, A. Tanioka, A. J. Flewitt, W. I. Milne, and G. A. J. Amaratunga, Appl. Phys. Lett. 93(13), 133116 (2008).

${ }^{8}$ J.-S. Na, B. Gong, G. Scarel, and G. N. Parsons, ACS Nano 3(10), 3191 (2009).

${ }^{9}$ W. Zhou and H.-b. Jin, J. Compos. Mater. 46(3), 291 (2011).

${ }^{10}$ K. Shankar and S. C. Lakkad, J. Mater. Sci. Lett. 1, 53 (1982); R. D. Adams and M. R. Maheri, J. Alloys Compd. 355(1-2), 126 (2003); R. Chandra, S. P. Singh, and K. Gupta, Composites, Part A 33(6), 787 (2002).

${ }^{11}$ S. W. Hudnut and D. D. L. Chung, Carbon 33(11), 1627 (1995).

${ }^{12}$ D. D. L. Chung, J. Alloys Compd. 355(1-2), 216 (2003).

${ }^{13}$ D. P. N. Vlasveld, H. E. N. Bersee, and S. J. Picken, Polymer 46(23), 10269 (2005).

${ }^{14}$ R. C. L. Dutra, B. G. Soares, E. A. Campos, and J. L. G. Silva, Polymer 41(10), 3841 (2000).

${ }^{15}$ L. Sun, R. F. Gibson, F. Gordaninejad, and J. Suhr, Compos. Sci. Technol. 69(14), 2392 (2009); X. Zhou, E. Shin, K. W. Wang, and C. E. Bakis, Compos. Sci. Technol. 64(15), 2425 (2004).

${ }^{16} \mathrm{Based}$ on the results obtained by the authors of this article.

${ }^{17}$ E. T. Thostenson and T. W. Chou, J. Phys. D: Appl. Phys. 35(16), L77 (2002).

${ }^{18}$ H. Rajoria and N. Jalili, Compos. Sci. Technol. 65(14), 2079 (2005).

${ }^{19}$ L. Jin, C. Bower, and O. Zhou, Appl. Phys. Lett. 73(9), 1197 (1998).

${ }^{20}$ F. H. Gojny, M. H. G. Wichmann, U. Kopke, B. Fiedler, and K. Schulte, Compos. Sci. Technol. 64(15), 2363 (2004).

${ }^{21}$ J. Suhr, N. Koratkar, P. Keblinski, and P. Ajayan, Nature Mater. 4(2), 134 (2005).

${ }^{22}$ S. Baruah and J. Dutta, Sci. Technol. Adv. Mater. 10(1), 013001 (2009).

${ }^{23}$ S. Xu and Z. L. Wang, Nano Res. 4(11), 1013 (2011).

${ }^{24}$ B. Xiang, P. Wang, X. Zhang, S. A. Dayeh, D. P. R. Aplin, C. Soci, D. Yu, and D. Wang, Nano Lett. 7(2), 323 (2007).

${ }^{25}$ L. Vayssieres, Adv. Mater. 15(5), 464 (2003).

${ }^{26}$ Q. Zhang, J. Liu, R. Sager, L. Dai, and J. Baur, Compos. Sci. Technol. 69(5), 594 (2009).

${ }^{27}$ Y. Lin, J. W. Shaffer, and H. A. Sodano, Smart Mater. Struct. 19(12), 124004 (2010); Y. Lin, G. Ehlert, and H. A. Sodano, Adv. Funct. Mater. 19(16), 2654 (2009).

${ }^{28}$ M. Sumita, H. Gohda, S. Asai, K. Miyasaka, A. Furuta, Y. Suzuki, and K. Uchino, Makromol. Chem., Rapid Commun. 12, 657 (1991); Z. Liu, Y. Wang, G. Huang, and J. Wu, J. Appl. Polym. Sci. 108(6), 3670 (2008). 